\title{
Expectations and outcomes: How technologies drive virtual teaching
}

\section{Hans Schuessler, Carlos Rodriguez, Alexandre Kolomenskii}

Department of Physics and Astronomy, Texas A\&M University, College Station, Texas, USA.

\begin{abstract}
We evaluate the effectiveness of using Zoom for learning Modern Physics topics in a large engineering physics class at a land-grant university in Texas. This virtual technology challenged both students and professors. By implementing different approaches: providing ahead of the lectures reading assignments, PowerPoint presentations, and pre-recorded videos, administering attendance mini-quizzes during the class and afterward, giving homework on WebAssign, elements of an effective virtual class setting complimented also by some asynchronous approaches were introduced. Passion and mutual understanding united students and instructors in active learning process helping to endure the challenging teaching environment. We describe the implementation of the technologies, the learning expectations and outcomes. The evaluation of outcomes was done in two ways: quantitatively, by statistical measures, and qualitatively, through an anonymous student survey and a university-wide teacher evaluation.
\end{abstract}

Keywords: Zoom virtual teaching and learning; undergraduate engineeringphysics class; student performance; surveys. 


\section{Introduction}

The COVID-19 pandemic in 2020 strongly affected or made impossible traditional classroom activities and forced the transition to methods relying more on modern communication technologies and remote learning, which is commonly labelled as e-learning. As disastrous as it is, this pandemic also motivates instructors to introduce novel teaching modalities, and embrace technological innovations (Popa et al.,2020; Anderton et al., 2021). The requirements of distance learning provide educators with an opportunity to explore new approaches as well as the merits and weaknesses of different aspects of e-learning.

Two modes of e-learning are distinguished: asynchronous and synchronous (O'Brien, 2020; Hrastinski, 2008). The first type is usually implemented with content available online for students to access at any time, and it commonly employs pre-recorded videos, email, and discussion boards. The second approach takes place in real time with a predetermined class schedule and required login times, but assignments must be completed by certain deadlines, and it uses a combination of videoconferencing and chat platforms (Zoom, WebEx, Skype, etc.). The commonly used in the literature term "virtual" learning refers to the synchronous approach, whereas another term "online" refers to asynchronous. The onset of the pandemic created conditions, which forced educators to urgently transition to e-learning methods of content delivery and interaction with students (Delgado,2021; Naciri et all., 2020). Such a transition put forward several challenges: (1) How to replicate the collaborative learning experience afforded by a physical classroom? (2) How to substitute physics demonstrations that relate theory with real world experiences? (3) How to encourage and maintain student engagement throughout the course?

In our teaching approach we used synchronous teaching delivering lectures and answering questions on Zoom, and we also used the asynchronous mode providing lecture recordings online and administering homework assignments with Webassign. Such a combination of the two approaches offered more flexibility to students for their optimal time management.The transition to online teaching requires relying on modern communication technology and providing study materials via the internet. In this paper, we describe the organization of the major components of the teaching process in a large public research-oriented institution, where undergraduate science lectures in physics are given for a class with hundreds of students. The final grades and the surveys conducted at the end of the semester show positive outcomes in the level of knowledge and problem-solving skills acquired by students as well as their overwhelming approval of the learning experience and the course as a whole.

\section{Technology and Course Organization}

Several aspects of the teaching process to which students pay particular attention (Blau, 2009) were addressed, and this determined the overall success of the course work. The course 
extensively relied on the resources placed on the internet and various communication means (Zoom, Google forms, surveys, homework with WebAssign, eCampus exams, and the class webpage). The course website contained all information relevant to the course, starting with the syllabus and instructions and including also lecture presentations and recordings, a direct link to send questions to the lecturer, as well as links to internet materials that would illustrate and complement the topics discussed on the lectures. Google Forms were used for questions that students could ask any time, if they needed more detailed explanations. The course website also presented exam preparation instructions and a summary of the functions of the lockdown browser Respondus. The class interaction with students went through Zoom, and all the links were also integrated into Canvas and eCampus and allowed for efficient interaction between students and content, students and the professor, and among students. Canvas is a course management system and eCampus is the university supported learning management system. Homework was completed through Webassign (online instructional application for faculty and students, acquired by Cengage). The course Modern Physics covers relativity, models of the atom, an introduction to quantum mechanics, atomic physics, nuclear physics, and modern astrophysics. As a prerequisite, a student must have a working knowledge of geometry, algebra, calculus and be proficient in the use of vectors. This online course required students to be able to access the online course content, assuming usage of a computer and internet connection. In addition, to verify student identities during exams, a web camera was required. The students were supposed to achieve the following conceptual learning outcomes: (1) Understanding of the physical laws of the topics described above. (2) Learning about the historic context of the physical developments and their implications for science and technology today. (3) Learning to think critically/scientifically and developing the skills needed to attack complex problems.

Lectures were delivered online using Zoom video conferences. It was the students' responsibility to attend lectures regularly, and their attendance was monitored with short quizzes during the lectures, which also served to provide the feedback. In addition to the Google Forms, class interactions were performed through the use of breakout rooms, Zoom polls, and the raised hand/chat notifications that were available through the Zoom chat. The course TA was also available to answer student questions in real time through the Zoom chat. Because of the difficulty of having a dialogue in such a large class, especially since it was occurring virtually, live class question sheets were implemented. A Google form was opened before each lecture and students could submit questions they had about that day's material.

If the question was not answered in class, it was covered either in a personal email or at the start of the next class. Prerecorded video lectures have been uploaded to the class webpage. Their initial set was sequentially posted before each lecture and removed the day after the first exam. Then the next set covering the material of the second exam was available until the day after this exam. The posting of MP4 lecture videos continued in this way until the final 
exam. While these lectures could be watched at any time when made available, they were not considered a substitute to class lectures, as they are prerecorded and did not allow the same level of interaction as a live lecture. While homework contributed "only" $15 \%$ to the grade, its importance for the learning success was highly emphasized. Exams generally consisted of problems similar in content and difficulty to the homework, and they included both multiplechoice and short free-response questions. Exams were open book and open notes, but students had to work independently, and seeking outside help from anyone or through answer services was not allowed. In order to proctor the exams remotely, especially with such a large class, exams were conducted only with the use of the Respondus LockDown Browser. This browser, unlike other more common web-browsers (such as Google Chrome, Edge, Firefox, etc.) opens only if all other applications on the computer are closed, and it does not allow any other programs to be opened during the exam. Additionally, Respondus makes use of the computer's camera and microphone ensuring that only the student himself is taking the exam without any outside help. Should any suspicious activity occur, Respondus flags it and records the activity for later review by the instructor. Respondus itself does not determine if violation of test protocols has occurred. At the conclusion of the course, students were asked to fill out an optional survey about their demographics and opinions on the course. This survey was conducted through a Google form emailed out to the students during the final two weeks of the course, and all information student provided was voluntary. One of the advantages of an online class was that even students with mild illness and those on quarantine could participate in the course-related activities remotely, not affecting other students.

a)

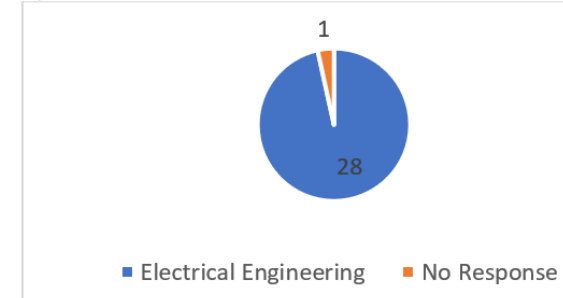

c)

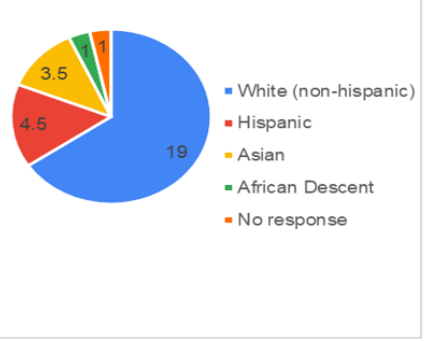

b)

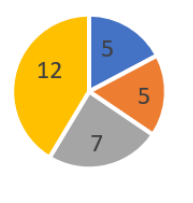

- $0=1=2=3$

d)

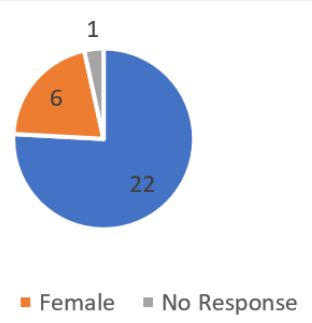

Figure 1. a) Breakdown of student majors. b) Time in years students have spent at Texas A\&M. A response of 0 indicates first semester student. c) Breakdown of student ethnicity. d) Breakdown of student gender. 
Table 1. Instructor's Survey. Questions and Student Responses.

\begin{tabular}{|c|c|}
\hline Questions & Student Responses $(n=21)$, three select responses represented here. \\
\hline $\begin{array}{l}\text { Were the Zoom } \\
\text { lectures a reasonable } \\
\text { substitute for face- } \\
\text { to-face teaching? }\end{array}$ & $\begin{array}{l}\text { 1. Yes, I think for the most part Zoom lectures were okay. The pre-recorded } \\
\text { lectures were nice to have to go back to. } \\
\text { 2. Yes, all of the information was provided by the slides. } \\
\text { 3. To get material across yes, for an overall learning experience no. }\end{array}$ \\
\hline $\begin{array}{l}\text { Was the use of the } \\
\text { lockdown browser } \\
\text { and class attendance } \\
\text { quizzes appropriate? }\end{array}$ & $\begin{array}{l}\text { 1. The lockdown browser feels the most questionable because of privacy concerns. } \\
\text { 2. No. Since everything was open note, lockdown browser only posed as an extra } \\
\text { hurdle which gave few students issues. A proctored zoom call could likely suffice. } \\
\text { 3. Yes, it never felt overused. }\end{array}$ \\
\hline $\begin{array}{l}\text { Which aspects of the } \\
\text { course facilitated } \\
\text { your learning? }\end{array}$ & $\begin{array}{l}\text { 1. The homeworks and the lectures are where I gained most of my knowledge from. } \\
\text { I think the Webassign homework is good. } \\
2 \text {. The engagement of the class in chat and actual passion by the professor. } \\
\text { 3. The practice quizzes on Cengage, the homeworks were very helpful for the test, } \\
\text { and having class website really helped me feel organized in this class. }\end{array}$ \\
\hline $\begin{array}{l}\text { Which aspects of the } \\
\text { course impeded your } \\
\text { learning? }\end{array}$ & $\begin{array}{l}\text { 1. I wouldn't say any part of the course in the professor's control impeded my } \\
\text { learning. } \\
\text { 2. Nothing really. It was a good atmosphere to be in for me. } \\
\text { 3. Some of the lectures were definitely hard to follow, because some slides were } \\
\text { skipped and others were on screen for a long time. }\end{array}$ \\
\hline $\begin{array}{l}\text { What can be done to } \\
\text { overcome any } \\
\text { learning obstacles } \\
\text { you experience in } \\
\text { this course? }\end{array}$ & $\begin{array}{l}\text { 1. The professors thought because it's not in person we have more time to study the } \\
\text { material, but I found that to be the exact opposite. } \\
\text { 2. If anything, lab demonstrations, although over zoom it would be very difficult, } \\
\text { unfortunately } \\
\text { 3. I just need to study the material and do the quizzes more. }\end{array}$ \\
\hline $\begin{array}{l}\text { Were the posted } \\
\text { video recordings } \\
\text { helpful? }\end{array}$ & $\begin{array}{l}\text { 1. Yes, the recordings were beneficial, especially if I wasn't able to attend class. } \\
\text { 2. I didn't look at any, because I always attended lectures and everything taught was } \\
\text { on slides or was easily answered by the TA. } \\
\text { 3. Yes, even though I only used them once. }\end{array}$ \\
\hline $\begin{array}{l}\text { Were the posted } \\
\text { lecture PowerPoints } \\
\text { helpful? }\end{array}$ & $\begin{array}{l}\text { 1. Yes, equally as beneficial as having the lectures recorded. } \\
\text { 2. Very much so. } \\
\text { 3. Very! }\end{array}$ \\
\hline
\end{tabular}

\section{Evaluation and Outcomes}

\subsection{Survey on Student demographics, Suggestions and Comments for the Course}

This survey conducted by the instructor was meant to give an overview of student demographics, opinions on how the course was conducted, and suggestions for improvements (see Table 1). A correlation between the extend students participated in class and their overall grade can be seen in Fig. 2. Students who participated often and earned a higher number of participation points tended to score better in the class overall. The larger amount of time spent on the homeworks led on average to higher grades (Fig. 3), however some of the students spent more time on the homeworks not achieving the highest grades (the right side of the graph). 


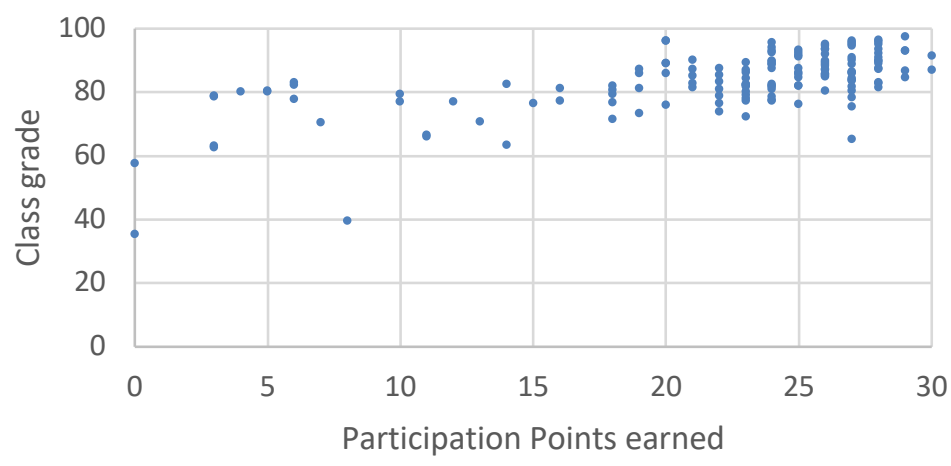

Figure 3. Student participation points vs the final grade earned in the class.

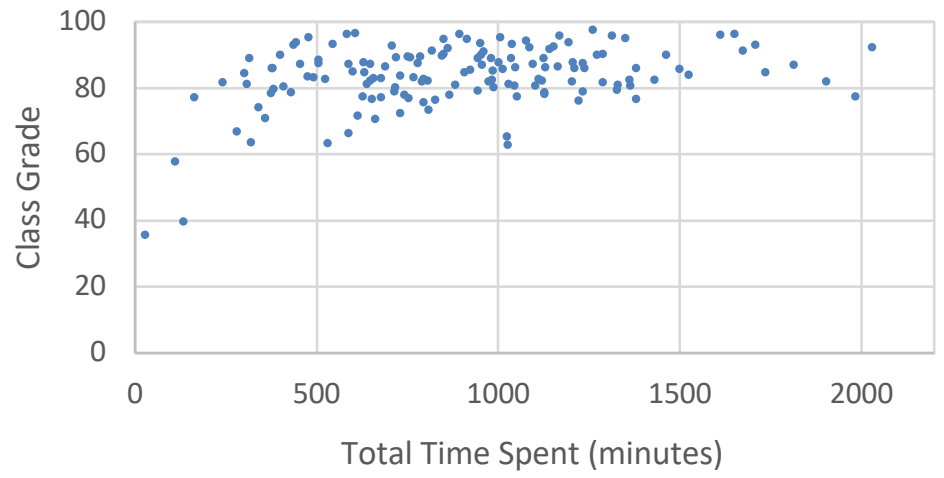

Figure 2. Time student spent on homework vs the final grade earned in the class.

\subsection{University Student Course Evaluation}

The use of student course evaluations can be a highly effective way to provide feedback to instructors about the student experience. This course evaluation invited students to contemplate on different aspects of the course and indicate what class preparation activities (e.g., readings, online modules, videos and assignments) were most helpful for them to learn the material and prepare for exams. 
Table 2. University Survey: Student Course Evaluations.

\begin{tabular}{|c|c|}
\hline Course Aspects & Student Evaluation Responses $(n=52), 3$ select responses represented here. \\
\hline $\begin{array}{l}\text { Based on what the } \\
\text { instructor(s) } \\
\text { communicated, and the } \\
\text { information provided in } \\
\text { the course syllabus, I } \\
\text { understood what was } \\
\text { expected of me. }\end{array}$ & $\begin{array}{l}\text { 1. The professor and TA outlined exactly what was expected from us at the } \\
\text { beginning of the semester, and this was very helpful. } \\
2 \text {. The syllabus well explained the course outline, schedule, and main componets of } \\
\text { the course. } \\
\text { 3. I liked that I always could ask questions and get answers. }\end{array}$ \\
\hline $\begin{array}{l}\text { This course helped me } \\
\text { learn concepts or skills as } \\
\text { stated in course } \\
\text { objectives/outcomes. }\end{array}$ & $\begin{array}{l}\text { 1. This course definitely helped me learn the concepts/skills. } \\
\text { 2. The slideshows/lectures and practice problems were all very helpful in allowing } \\
\text { me to reach the objectives of this course. } \\
\text { 3. Very interesting subject matter. }\end{array}$ \\
\hline $\begin{array}{l}\text { Please rate the } \\
\text { organization of this } \\
\text { course. }\end{array}$ & $\begin{array}{l}\text { 1. Very well organized. All of the materials were located in the eCampus and were } \\
\text { easy to find. } \\
\text { 2. Everything was appropriately laid out from beginning to end with minor } \\
\text { adjustments along the way that didn't disrupt the curriculum. } \\
\text { 3. Clear due dates and layout of coursework. Course website was really helpful. }\end{array}$ \\
\hline $\begin{array}{l}\text { Feedback in this course } \\
\text { helped me learn. }\end{array}$ & $\begin{array}{l}\text { 1. Feedback provided was extremely helpful. Both the professor and TA always } \\
\text { encouraged us to ask questions, and were very clear in their responses to the class. } \\
\text { 2. The TA was awesome. Professor was very caring and knowledgeable. } \\
\text { 3.Feedback was given in attendance quizzes, indicating our understanding. } \\
\text { Professor clearly explaned the problems during lecture. }\end{array}$ \\
\hline $\begin{array}{l}\text { The instructor fostered an } \\
\text { effective learning } \\
\text { environment. }\end{array}$ & $\begin{array}{l}\text { 1. Strongly agree. Professor was very passionate about his work. } \\
\text { 2. The professor was engaging as an instructor and enjoyable to learn from. } \\
\text { 3. Wonderful instructor. Very motivated and always wants to help his students. }\end{array}$ \\
\hline $\begin{array}{l}\text { The instructor } \\
\text { encouraged students to } \\
\text { take responsibility for } \\
\text { their own learning. }\end{array}$ & $\begin{array}{l}\text { 1. Frequently encouraged. } \\
\text { 2. He always recommended reading the chapters before lecture, and it helped. } \\
\text { 3. Yes, you had to actually study to do well in the class. }\end{array}$ \\
\hline
\end{tabular}

In addition, in the discussions of the advantages and disadvantages of the virtual learning students mentioned the following positive aspects of this approach: (1) Online lectures help to attend late-night classes and with accessibility issues (e.g., bad weather, distant locations), saved a lot of time (no need to drive, find parking or walk). (2) Zoom has the chat and breakout rooms, making it possible to answer short questions in real-time. It is very convenient to have the professor and the TA offering office hours on Zoom - there is no need to rush around campus. (3) It is very helpful to have all lectures recorded, as one can go back and re-watch for deeper understanding. (4) The internet environment is more flexible and has helped to develop a better routine, but it requires good time management to avoid procrastination. However, some aspects were negative: (1) Students missed face-to-face communication and forming connections with peers and faculty. (2) Laboratory work, demonstrations, study on group projects were missing. Consequently, still more improvements are needed. 


\section{Summary and Outlook}

Taking into account students' level of acquired knowledge, their grades and evaluations of this virtual course, we conclude that overall it was a success. Several aspects contributed to this positive outcome: (1) the course was well organized and all aspects of the course as well as the expectations were well described; (2) the course inherently had a modular structure; (3) questions-answers sessions, office hours, quizzes and e-mail messages allowed to realize an efficient feedback from the students, so the instructor and the TA could timely respond to the questions and address material misconception and misunderstandings.

In the future, we will explore several additions to the arsenal of our teaching methods. To take advantages of learning in a social context, which is commonly considered an effective approach to learning (Dunlap et al., 2009), learning in groups using breakout rooms in Zoom will be further investigated. Usage of smartphones as an educational tool also deserves some thorough consideration (Moradi et al., 2018). The lack of experimental demonstrations can be compensated by the introduction of software-based simulations and environment of augmented reality (Khan et al., 2020), especially taking into account fast development of cloud computing and the achievements in the fast data transfer that will be even more enhanced with the general adaptation of $5 \mathrm{G}$ networks.

\section{Acknowledgments}

This work was supported by the Presidential Transformational Teaching Grant of Texas A\&M University (PTTG 20) and by the Robert A. Welch Foundation Grant No. A1546.

\section{References}

Anderton, R., Vitali, J., Blackmore, C., \& Bakeberg, M. (2021). Flexible Teaching and Learning Modalities in Undergraduate Science Amid the COVID-19 Pandemic, Front. Educ., 14(1), 1-7. doi: 10.3389/feduc.2020.609703

Blau, I. (2009). Online Teaching Effectiveness: A Tale of Two Instructors, International Review of Research in Open and Distance Learning, 10(3), 1-27. doi: 10.19173/irrodl.v10i3.712

Delgado, F. (2021). Teaching Physics for Computer Science Students in Higher Education During the COVID-19 Pandemic: A Fully Internet-Supported Course, Future Internet 13(35),1-24. doi: 10.3390/fi13020035

Dunlap, J., Furtak, T., \& Tucker, S. (2009). Designing for Enhanced Conceptual Understanding in an Online Physics Course, TechTrends, 53(1), 67-73. https://link.springer.com/article/10.1007/s11528-009-0239-0

Hrastinski, S. (2008). Asynchronous and Synchronous E-Learning, EDUCAUSE Quarterly, $\quad 31(4), \quad 1-9 . \quad$ https://er.educause.edu/-/media/files/articledownloads/eqm0848.pdf 
Khan, S., Rabbani, R., Thalassinos, I., \& Atif, M. (2020). Corona Virus Pandemic Paving Ways to Next Generation of Learning and Teaching: Futuristic Cloud Based Educational Model. Available at SSRN: 3669832.

Moradi, M., Liu L., Luchies, C., Patterson, M., \& Darban, B. (2018). Enhancing TeachingLearning Effectiveness by Creating Online Interactive Instructional Modules for Fundamental Concepts of Physics and Mathematics, Education Sciences, 8(3), 1-14. doi: 10.3390/educsci8030109

Naciri, A., Baba, M.A., Achbani, A., \& Kharbach, A. (2020). Mobile Learning in Higher Education: Unavoidable Alternative during COVID-19, Aquademia 4(1), ep20016. doi:10.29333/aquademia/8227

O'Brien D. (2020). Feynman, Lewin, and Einstein Download Zoom: A Guide for Incorporating E-Teaching of Physics in a Post-COVID World. https://arxiv.org/abs/2008.07441

Popa, D., Repanovici, A., Lupu, D., Norel, M. \& Coman, C. (2020). Using Mixed Methods to Understand Teaching and Learning in COVID 19 Times, Sustainability, 12(20), 1-20. doi: $2071-1050 / 12 / 20 / 8726$ 